\section{Reduction in unstimulated salivary flow rate in burning mouth syndrome}

\author{
R. Poon, ${ }^{1}$ N. Su, ${ }^{2}$ V. Ching, ${ }^{3}$ M. Darling ${ }^{4}$ and M. Grushka ${ }^{* 5}$
}

IN B RIEF
- Enhances the diagnosis of burning mouth
- Dyndrome (BMS).
Differentiates between BMS and
- Högren's patients.
- simple tool fortial to become a very
- Suggests that one of the aetiologies
of BMS relates to autonomic nervous
system dysfunction.

\begin{abstract}
Background Burning mouth syndrome (BMS) is a chronic condition of burning of the tongue and oral mucosa. It is often accompanied with complaints of xerostomia, although it is unknown whether the dryness is a sensory change similar to the burning sensation or due to hyposalivation. To determine whether there is change in salivary flow rate, whole salivary flows were measured in BMS patients. Methods A clinical ambispective study was conducted. Patients' clinical files were reviewed for stimulated and unstimulated whole salivary flow. Patients were divided into four groups based on diagnosis into Sjögren's syndrome (SS), BMS, BMS taking oral drying medications (BMS-med), and control (C). Whole stimulated (SF) and unstimulated flow (USF) measurements were collected and compared among groups. Data were analysed with ANOVA, Levene's test, Tukey's test and Games-Howell test. Results Twenty SS, 22 BMS, 24 BMS-med and 15 C were included in the study. SF was significantly lower in SS (0.59 ml \pm 0.36$)$ compared with BMS $(1.56 \mathrm{ml} \pm 0.65, \mathrm{p}<0.001)$, BMS-med $(1.44 \mathrm{ml} \pm 0.64, p<0.001)$ and $\mathrm{C}(2.32 \mathrm{ml} \pm 1.06, \mathrm{p}=0.001)$. USF was significantly lower in $\mathrm{SS}(0.12 \mathrm{ml} \pm 0.10)$ compared with BMS $(0.30 \mathrm{ml} \pm 0.18$, $p=0.002)$, BMS-med $(0.27 \mathrm{ml} \pm 0.21, p=0.022)$ and $C(0.52 \mathrm{ml} \pm 0.26, p<0.001)$. SF was not significantly different between BMS and $C(p=0.172)$ and BMS-med and C ( $p=0.096)$. Both BMS and BMS-med had significantly lower USF compared with $C$ ( $p=0.040$ and $p=0.018$ respectively). SF in BMS was not significantly affected by number of oral drying medications $(p=0.254)$; however, USF was significantly lower with two or more oral drying medications $(0.13 \mathrm{ml} \pm 0.07)$ compared with one oral drying medication $(0.32 \mathrm{ml} \pm 0.22)(p=0.034)$. Conclusion BMS patients have statistically significant decreased unstimulated salivary flow rate with non-statistically significant decreased stimulated flow rate. Salivary flow rates in BMS patients are decreased further by medication usage whose side effects include dry mouth. This suggests that hyposalivation may play a role in causing dry mouth in BMS, which may respond to treatment with a sialogogue.
\end{abstract}

\section{INTRODUCTION}

Burning mouth syndrome (BMS) is a chronic condition characterised by burning pain of the tongue and other oral areas, including the palate, lips and gingival tissues, with usually normal local and systemic findings. ${ }^{1,2}$ BMS is therefore often considered a neuropathic phenomenon and it has been suggested that the aetiology of the spontaneous pain is due to loss of tonic inhibition of the trigeminal nerve ( $\mathrm{CN} \mathrm{V}$ ) by damage to the taste system carried by the facial (CN VII), glossopharyngeal (CN IX)

${ }^{1}$ Private Practice in Oral Medicine: ${ }^{2}$ Norman Bethune College of Medicine, Changchun, China; ${ }^{3}$ Manitoulin Health Centre; ${ }^{4}$ Associate Professor, Division of Oral Pathology, Department of Pathology, Schulich School of Medicine and Dentistry, University of Western Ontario Canada; ${ }^{5}$ Department of Dentistry, William Osler Hospital (Etobicoke), Toronto, Canada

*Correspondence to: Dr Miriam Grushka

Email: miriamgrushka@gmail.com

Online article number E14

Refereed Paper - accepted 22 July 2014

DOI: 10.1038/sj.bdj.2014.884

${ }^{\circledR}$ British Dental Journal 2014; 217: E14 and vagus (CNX) nerves. ${ }^{3}$ This is consistent with the recent literature demonstrating the presence of taste loss and distortion in patients with BMS. ${ }^{4,5}$ In addition to supplying gustatory sensation in the mouth, cranial nerves VII, IX, and X also mediate salivary secretion. ${ }^{6-8}$

BMS is often reported to be associated with xerostomia or a sensation of oral dryness, ${ }^{9}$ however, this is usually believed to be related to a symptomatic change in somatosensation similar to the burning sensation, rather than an actual lack of saliva. ${ }^{10}$ It has also been suggested that change in salivary composition may be responsible for changes in oral sensation. Sialometrical analysis showed elevation of sodium, total protein, albumin, IgA, IgG, IgM and lysozyme in BMS patients similar to those seen in patients with xerostomia. ${ }^{11}$ However, in our clinical observation, BMS patients have consistently shown a reduced unstimulated salivary flow rate while retaining a normal stimulated flow rate. We hypothesize that the xerostomia reported by BMS patients may be due to an actual reduction in the unstimulated salivary flow rate. To verify whether there is change in salivary flow rate in BMS, in this study salivary flow rates of BMS patients were compared with those in Sjögren's syndrome (SS) patients with known changes to the salivary glands and control subjects without a diagnosis of SS or BMS.

\section{MATERIAL AND METHODS}

Retrospective chart review of consultation and clinical notes from patients who presented for assessment at a private oral medicine and orofacial pain clinic in Toronto, Ontario between January 2009 to March 2012 by the same clinician (MG) was performed for whole stimulated and unstimulated salivary flow collection measurement.

Patient inclusion criteria include female gender, a diagnosis of BMS, SS, or other oral complaints including oral lesions, lichen planus or a contact sensitivity. The control group also included non-patient employee 
volunteers of the clinic who were not involved in the study. Prospective salivary collection was done for all volunteers. Volunteers were included in the control group if they were not taking any medications known to cause oral dryness, had no known oral issues and had given consent. Patients were included in the study if they met the inclusion criteria and had given written informed consent for anonymous use of their information for retrospective study.

A total of 66 patients and 15 controls were selected for the study. Out of the 66 patients, 46 were diagnosed with BMS in accordance with the International Association for the Study of Pain (IASP) and 20 patients were diagnosed with SS in accordance with the American European Consensus Group Criteria (AECC). ${ }^{12}$ The control group was made up of 15 participants including volunteers and patients who were diagnosed with oral lesions, lichen planus or a contact sensitivity and who were not using medications that are associated with oral dryness.

Medication is a known factor in causing dry mouth. ${ }^{13}$ We therefore divided BMS patients into two groups: those with (BMS-med) and without (BMS) oral drying medication.

For whole salivary flow measurement, all patients had stimulated (SF) and unstimulated flow (USF) collected at the time of their initial consultation. Patients were instructed to

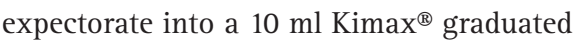
cylinder (Kimble Chase Life Science and Research Products LLC, Vineland, NJ) with accuracy of $0.1 \mathrm{ml}$. USF was collected after a minimum of 30 minutes at rest during which the patients did not eat, drink or chew gum. Patients were instructed to expectorate into a graduated cylinder for 5 minutes in a quiet room at rest without swallowing and any stimulations including chewing, drinking and speaking. SF collection was done following USF collection. Patients were instructed to chew on a paraffin pellet (as part of the Dentobuff ${ }^{\circledR}$ saliva analysis kit by Orion Diagnostica ${ }^{\mathrm{TM}}$, Espoo, Finland) and asked to expectorate for another 5 minutes without swallowing while chewing on the paraffin pellet. All salivary collections

\begin{tabular}{|c|c|c|c|}
\hline \multirow{2}{*}{ Groups } & \multirow{2}{*}{ USF (ml/min) } & \multicolumn{2}{|c|}{$95 \% \mathrm{Cl}$ for mean } \\
\hline & & Lower bound & Upper bound \\
\hline SS & $0.12 \pm 0.10^{*}$ & 0.07 & 0.17 \\
\hline BMS & $0.30 \pm 0.18^{*}$ & 0.22 & 0.38 \\
\hline BMS-med & $0.27 \pm 0.21^{*} * *$ & 0.18 & 0.35 \\
\hline C & $0.52 \pm 0.26^{* *}$ & 0.38 & 0.67 \\
\hline
\end{tabular}

Table 2 Stimulated flow rate (SF) presented as mean \pm standard deviation

\begin{tabular}{l|l|l|l}
\multirow{2}{*}{ Groups } & \multirow{2}{*}{ SF $(\mathrm{ml} / \mathrm{min})$} & $95 \% \mathrm{Cl}$ for mean \\
\cline { 3 - 4 } & & Lower bound & Upper bound \\
\hline SS & $0.59 \pm 0.36^{*}$ & 0.40 & 0.78 \\
\hline BMS & $1.56 \pm 0.65^{*}$ & 1.25 & 1.86 \\
\hline BMS-med & $1.44 \pm 0.64^{*}$ & 1.14 & 1.73 \\
\hline C & $2.33 \pm 1.06^{*}$ & 1.62 & 3.04 \\
\hline *SS had significantly lower SF compared with BMS (p<0.001), BMS-med $(p<0.001)$ and C $(p=0.001)$ \\
\hline
\end{tabular}

occurred during the daytime clinical hours between 9:30 am and 4:30 pm.

Data were analysed with Levene's test when there was unequal variance among groups, ANOVA, Games-Howell's test for pairwise comparison when variance was unequal between comparison groups and Tukey's test with a level of significance of $\mathrm{p}=0.05$.

This study received ethics review and approval from the REB/IRB group at William Osler Health System.

\section{RESULTS}

Eighty-one female patients were included in the study and were divided into four groups, 22 BMS patients, 24 BMS-med patients, 20 SS patients and 15 controls (C). Average ages were $58 \pm 14$ for SS, $57 \pm 11$ for BMS, $63 \pm 11$ for BMS-med and $53 \pm 10$ for $C$ $(p=0.076)$.

In the SS group, USF $(0.12 \mathrm{ml} \pm 0.10)$ was significantly below BMS $(0.30 \mathrm{ml} \pm 0.18$, $\mathrm{p}=0.002)$, BMS-med $(0.27 \mathrm{ml} \pm 0.21$, $\mathrm{p}=0.022)$ and $\mathrm{C}(0.52 \mathrm{ml} \pm 0.26, \mathrm{p}<0.001)$ groups and SF $(0.59 \mathrm{ml} \pm 0.36)$ was significantly below BMS (1.56 ml \pm 0.65 , $\mathrm{p}<0.001)$, BMS-med $(1.44 \mathrm{ml} \pm 0.64$, $\mathrm{p}<0.001)$, and $\mathrm{C}(2.33 \mathrm{ml} \pm 1.06, \mathrm{p}=0.001)$ (Tables 1 and 2).

The BMS group did not differ significantly from the BMS-med group in either USF or SF ( $p=0.947, p=0.935$ respectively) and was not significantly different in SF than the $C$ group $(p=0.172)$. However, the BMS group had significantly lower USF than the $C$ group ( $p=0.040$ ). The BMS-med group had significantly lower USF but non-significant SF when compared with the $\mathrm{C}$ group $(\mathrm{p}=0.018$ and $\mathrm{p}=0.096)$ (Table 2 and 3$)$.

To determine whether the number of oral drying medications affected flow rates in BMS-med, comparison of USF and SF was done for BMS-med patients taking one oral drying medication $(\mathrm{n}=17)$ and those taking two or more oral drying medications $(n=7)$.

Table 3 Effect of the number of medications on SF and USF among BMS patients presented as mean \pm standard deviation. There was no significant differences between SF ( $p=0.254)$

\begin{tabular}{|l|l|l|l|l|l|l|l|l|}
\hline Number of Medication & No. & USF (ml/min) & \multicolumn{2}{|l|}{$95 \%$ Cl for USF mean } & SF (ml/min) & \multicolumn{2}{l}{$95 \% \mathrm{Cl}$ for SF mean } \\
\hline 0 & & & Lower bound & Upper bound & & \multicolumn{2}{l}{ Lower bound } & Upper bound \\
\hline 1 & 22 & $0.30 \pm 0.18$ & 0.22 & 0.38 & $1.56 \pm 0.65$ & 1.25 & 1.86 \\
\hline$>2$ & 17 & $0.32 \pm 0.22^{*}$ & 0.21 & 0.43 & $1.55 \pm 0.72$ & 1.13 & 1.96 \\
\hline
\end{tabular}


There were no significant differences between SF $(p=0.254)$. USF was significantly lower when patients were taking two or more oral drying medications $(0.13 \mathrm{ml} \pm 0.07)$ compared with patients taking only one oral drying medication $(0.32 \mathrm{ml} \pm 0.22)$ $(p=0.034)$ (Table 3).

\section{DISCUSSION}

Clinically, BMS is often accompanied by complaints of xerostomia in additional to a burning sensation on the tongue and/or oral mucosa. ${ }^{14}$ Since examination of the oral cavity often yields no structural change for the cause of the discomfort, the sensation of oral dryness in BMS has sometimes been thought of as a sensory change, rather than due to a reduction in salivation.

BMS patients are often over the age of 50 years and it has been thought that age may be associated with oral dryness in an older population, perhaps as a result of increased medication, especially those with anticholinergic effect. ${ }^{2,13,15-17}$ In our study, however, when medication usage was taken into account, no significant differences were found between BMS and BMS-med groups, suggesting that oral dryness experienced by BMS patients is not significantly affected by medication. However, with multiple medications that can cause dry mouth, a significant decrease in USF and SF was seen, suggesting that medication usage is only a small factor in those patients using more than one medication.

Nagler and Hershkovich ${ }^{11}$ reported no significant difference in unstimulated salivary flow rate between BMS and controls and Zhao et al. ${ }^{18}$ reported non-statistically significant decrease in unstimulated flow rate in BMS compared with controls. However, in our study, although xerostomia in BMS does not appear to be accompanied by the severe hyposalivation seen in SS patients, a statistically significant reduction in unstimulated flow rate was observed in BMS patients when compared with controls, regardless of medication usage, suggesting evidence of hyposalivation in BMS when at rest.

Stimulated flow rate was decreased by approximately 33\% in BMS compared with controls and by approximately $38 \%$ in BMSmed, although these were not statistically significant.

It has been shown that chorda tympani damage as a result of stapedectomy can produce burning mouth syndrome postoperation associated with hyposalivation, with a pattern of decreased unstimulated flow with normal stimulated flow. ${ }^{19}$ The chorda tympani carry parasympathetic secretomotor innervation to the submandibular and sublingual salivary glands and minor glands of the floor of the mouth. ${ }^{6,20}$ Damage to the chorda tympani is thought to occur in BMS, which may lead to decreased function of the submandibular and sublingual glands. ${ }^{3,5,21,22}$ With chorda tympani innervation loss, the submandibular gland has been found to secrete considerably reduced saliva under stimulation. ${ }^{23}$ The reduction in unstimulated salivary flow rate found in BMS patients may therefore be due to the loss of parasympathetic secretomotor innervation carried by the chorda tympani, which is further reduced with the impact of the medication usage.

Several factors including long-term and heavy smoking, level of hydration, diurnal patterns, and gland size are known to affect salivary flow. ${ }^{24,25}$ Due to the retrospective design of the study, these factors were not included in the study. The retrospective design of the study is also limited in that information accuracy cannot be determined and the lack of information, such as activity before consultation could not be acquired.

\section{CONCLUSION}

This clinical study identified a statistically significant decrease in the unstimulated flow rate and non-statistically significant reduction in stimulated salivary flow rates in BMS patients regardless of medication usage. This provides the probability that mild hyposalivation may exist as one of the causes for the complaint of oral dryness and also suggests that the use of a sialogogue (for example, Pilocarpine) at times of rest may be helpful in burning mouth syndrome.

Ethics review approved by William Osler Health Centre. There was no conflict of interest or financial support for this study.

1. Grushka M, Ching V, Epstein J. Burning mouth syndrome. Adv Otorhinolaryngol 2006; 63: 278-287.

2. Grushka M. Clinical features of burning mouth syndrome. Oral Surg Oral Med Oral Pathol 1987 63: 30-36.

3. Bartoshuk L M, Catalanotto $F_{\text {, Hoffman }} \mathrm{H}_{\text {, }}$ Logan H, Snyder D J. Taste damage (otitis media, tonsillectomy and head and neck cancer), oral sensations and BMI. Physiol Behav 2012; 107 : 516-526.

4. Just T, Steiner S, Pau H W. Oral pain perception and taste in burning mouth syndrome. J Oral Pathol Med 2010; 39: 22-27.

5. Eliav E, Kamran B, Schaham R, Czerninski R, Gracely $\mathrm{R} \mathrm{H}$, Benoliel R. Evidence of chorda tympani dysfunction in patients with burning mouth syndrome. J Am Dent Assoc 2007; 138: 628-633.

6. Liebgott B. The anatomical basis of dentistry. 2nd ed. St. Louis: Mosby, 2001.

7. Veillona F, Ramos-Taboada L, Abu-Eid M, Charpiot A, Riehm S. Imaging of the facial nerve. Eur J Radiol 2010; 74: 341-348.

8. Gillig P M, Sanders R D. Cranial nerves $I X, X, X I$, and XII. Psychiatry (Edgmont) 2010; 7: 37-41.

9. Klasser G D, Fischer D J, Epstein J B. Burning mouth syndrome: recognition, understanding, and management. Oral Maxillofac Surg Clin North Am 2008; 20: 255-271.

10. Grushka M, Epstein J B, Kawalec J S. Burning mouth syndrome. In Silverman S, Eversole I R, Truelove $E$ L, (eds) Essentials of oral medicine. pp 354-358. Hamilton, ON: BC Decker Inc, 2001.

11. Nagler R M, Hershkovich O. Sialochemical and gustatory analysis in patients with oral sensory complaints. J Pain 2004; 5: 56-63.

12. Sankar V, Noll J L, Brennan M T. Diagnosis of Sjogren's syndrome: American-European and the American College of Rheumatology classification criteria. Oral Maxillofac Surg Clin North Am 2014; 26: 13-22.

13. Scully C. Drug effects on salivary glands: dry mouth. Oral Dis 2003; 9: 165-176.

14. Grushka M, Epstein J B, Gorsky M. Burning mouth syndrome and other oral sensory disorders: a unifying hypothesis. Pain Res Manag 2003; 8: 133-135.

15. Bergdahl M, Bergdahl J. Burning mouth syndrome: prevalence and associated factors. J Oral Pathol Med 1999; 28: 350-354.

16. Syrjala A M, Raatikainen $L$, Komulainen K et al. Salivary flow rate and periodontal infection- a study among subjects aged 75 years or older. Oral Dis 2011; 17: 387-392.

17. Shetty S R, Bhowmick S, Castelino R, Babu S. Drug induced xerostomia in elderly individuals: An institutional study. Contemp Clin Dent 2012; 3: 173-175.

18. Zhao M, Chen $\mathrm{Q}$, Lin M. [Relationship between the symptom of xerostomia and non-stimulated salivary flow rates in patients with burning mouth syndrome]. Hua Xi Kou Qiang Yi Xue Za Zhi 2001; 19: 169-170, 77.

19. Mandel L. Hyposalivation after undergoing stapedectomy. J Am Dent Assoc 2012; 143: 39-42.

20. Proctor $G B$, Carpenter $G H$. Regulation of salivary gland function by autonomic nerves. Auton Neurosci 2007; 133: 3-18.

21. Nasri-Heir C, Gomes J, Heir G M et al. The role of sensory input of the chorda tympani nerve and the number of fungiform papillae in burning mouth syndrome. Oral Surg Oral Med Oral Pathol Oral Radiol Endod 2011; 112: 65-72.

22. Bartoshuk $L M$, Catalanotto $F$, Hoffman $H$, Logan H, Snyder D J. Taste damage (otitis media, tonsillectomy and head and neck cancer), oral sensations and BMI. Physiol Behav 2012; 107: 516-526.

23. McManus L J, Stringer M D, Dawes P J. Clinical anatomy of the chorda tympani: a systematic review. J Laryngol Otol 2011; 125: 1101-1108.

24. Dawes C. Salivary flow patterns and the health of hard and soft oral tissues. J Am Dent Assoc 2008; 139: 18S-24S.

25. Dyasanoor S, Saddu S C. Association of xerostomia and assessment of Salivary flow using modified Schirmer test among smokers and healthy individuals: A preliminutesary study. J Clin Diagn Res 2014; 8: 211-213. 